\title{
Impact of Isometric and Isotonic Movements during Hemodialysis on Dialysis Adequacy
}

\author{
Basiri Moghaddam M.1 MSc, Mohamadpour A. ${ }^{2}$ PhD, Mottaghi M.R. ${ }^{3}$ MSc, Jahani Maghani F. ${ }^{*}$ BSc
}

*Student Research Committee, Nursing \& Midwifery Faculty, Gonadad University of Medical Sciences, Gonabad, Iran

${ }^{1}$ Internal Surgery Nursing Department, Nursing \& Midwifery Faculty, Gonabad University of Medical Sciences, Gonabad, Iran

2"Social Determinants of Health Research Center" and "Internal Surgery Nursing Department, Nursing \& Midwifery Faculty", Gonabad University of Medical Sciences, Gonabad, Iran

${ }^{3}$ Basic Science Department, Paramedical School, Gonabad of Medical Sciences of, Gonabad, Iran

\begin{abstract}
Aims: Long term prognosis of hemodialysis patients are influenced by adequacy treatment. Thus, it is important to study the factors that improve the adequacy dialysis. The aim of this study was to determine the impact of isometric and isotonic movements during hemodialysis on dialysis adequacy.

Materials \& Methods: In this clinical trial in 2014, 50 patients in the two dialysis centers of Gonabad City and Qaen City, Iran, were selected by simple random sampling method and considering the inclusion criteria. The samples were randomly divided into two equal experimental and control groups. Experimental group patients performed isometric and isotonic movement according to tutorial film for 60 minutes in the first 2 hours of hemodialysis. These sport movement were repeated 3 times a week during hemodialysis session for 6 weeks. Dialysis adequacy was calculated before and after intervention in 2 groups. Data was analyzed by SPSS 14.5 software using independent T, Chi-square, Pearson- and Spearman correlation coefficients tests.

Findings: After the intervention, there was a significant difference between two groups in adequacy of dialysis $(\mathrm{p}=0.01)$, in a way that before intervention, $80 \%$ of patients in experimental group had dialysis adequacy less than 1.2 which was reduced to $40 \%$ after intervention. However, the number of patients with less than 1.2 adequacy of dialysis in control group was increased from 72 to $76 \%$.

Conclusion: Performing isometric and isotonic movements during hemodialysis improves the adequacy of dialysis in hemodialysis patients.

Keywords

Renal Dialysis [http://www.ncbi.nlm.nih.gov/mesh/68006435];

Isotonic Contraction [http://www.ncbi.nlm.nih.gov/mesh/68007551];

Isometric Contraction [http://www.ncbi.nlm.nih.gov/mesh/68007537];

Exercise [http://www.ncbi.nlm.nih.gov/mesh/68015444]
\end{abstract}

\footnotetext{
${ }^{*}$ Corresponding Author

Tel: +985157223028

Fax: +985157223814

Address: Nursing \& Midwifery Faculty, Gonabad University of Medical Sciences, Next to the Asian Road, Gonabad, Iran. Postal Code: $96917-93718$

f.jahani44@yahoo.com

Received: December 28, $2014 \quad$ Accepted: June 10, 2015 ePublished: December 15, 2015
} 


\section{مقدمه}

يكى از مشكلات بزرگ نظام سلامت و از علل مهم مرگومير و

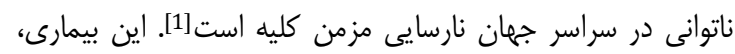

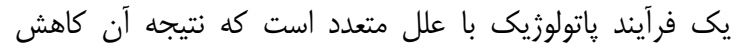

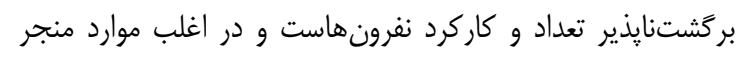

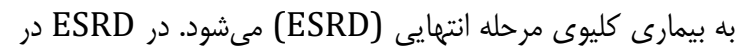

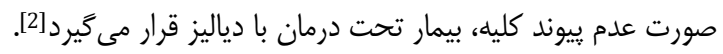

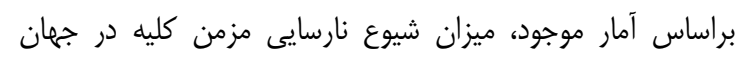
• عب مورد در هر يكميليون نفر جمعيت در سال است و و تقريباً

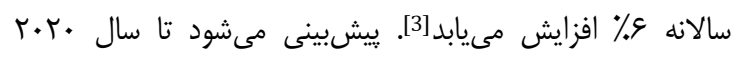

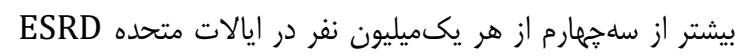

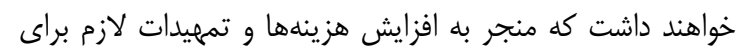

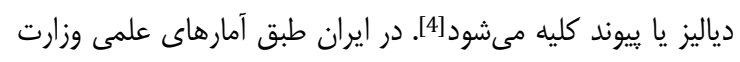

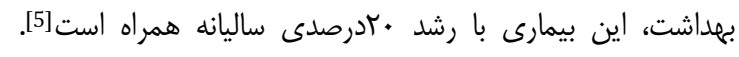

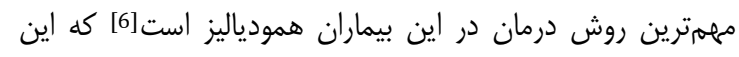

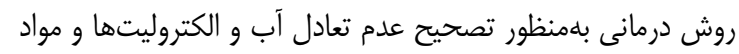

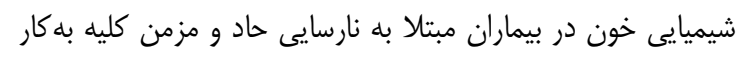
مىرود[5]. درمان با همودياليز علاوه بر عوارض در حين همودياليز مثل

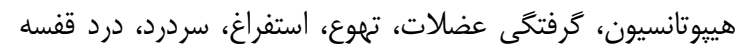

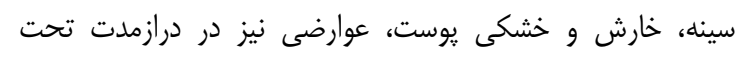

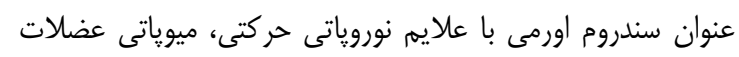
اسكلتى يا قلبى، تغييرات عروق بيرامونى، ناكارآيى متابوليزم استخوان، كاهش ظرفيت كار جسمانى، خستخى، افسردگى و و

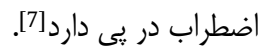
علىرغم بيشرفتهايى كه در امر مراقبت يزشكى و دياليز بهوجود

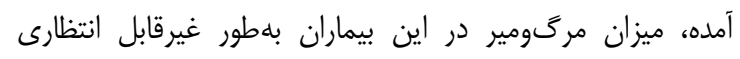

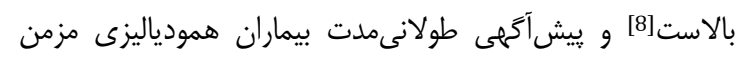

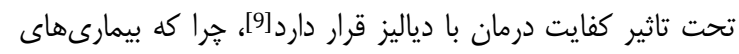

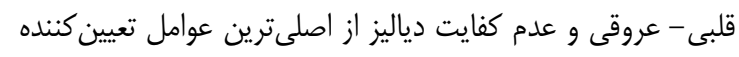

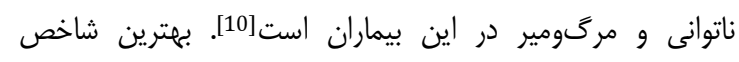
سنجش كفايت دياليز، زدودگى اوره است. در همودياليز كفايت

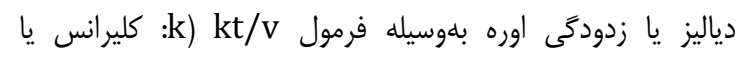

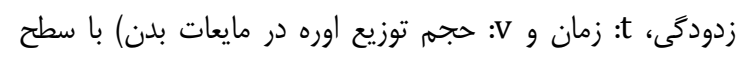

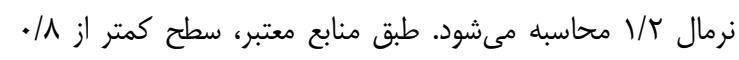

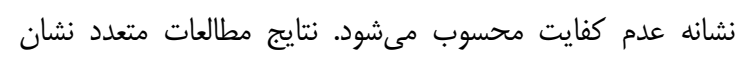

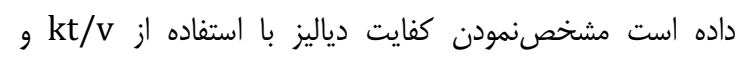

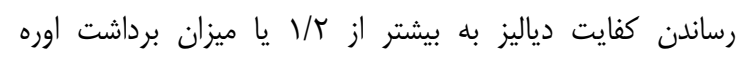

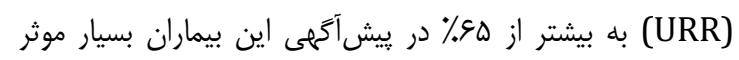
است[11] نتايج بررسىهاى انجامشده در ايران نشاندهنده كفايت پايين دياليز

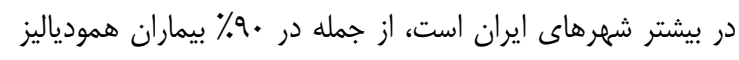

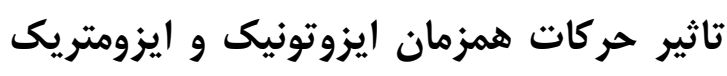
حين همودياليز بر كفايت دياليز

MSc مهدى بصيرى مقدم

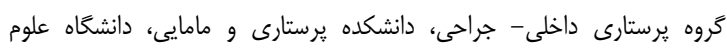
يز شكى گَناباد، كناباد، ايران

على محمديور PhD

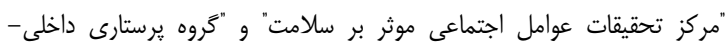

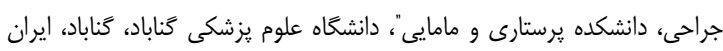

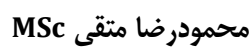

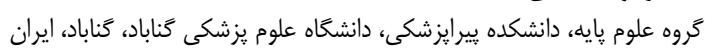

BSc "فاطمه جهانى مغانى

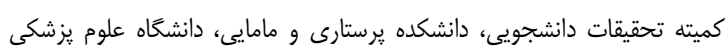

كناباد، كناباد، ايران تحقيقات دانش

اهذيده:

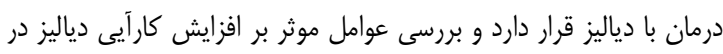

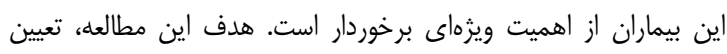

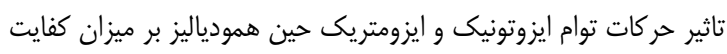

دياليز بيماران همودياليزى بود.

مواد و روشها: در اين كارآزمايى بالينى، •ه بيمار همودياليزى در دو دوداليز

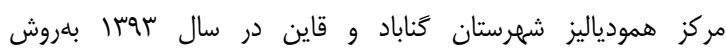

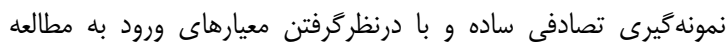

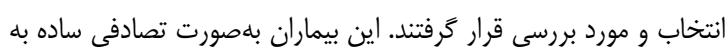

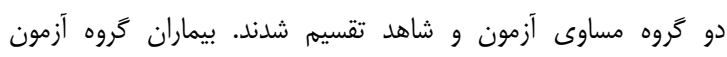

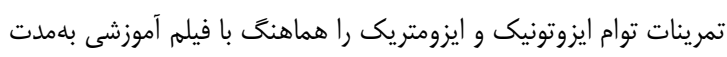

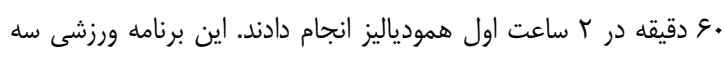

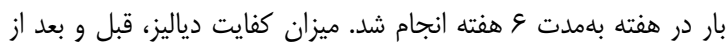

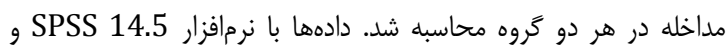

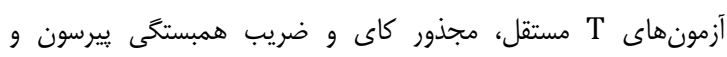

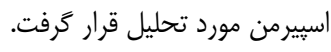

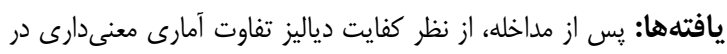

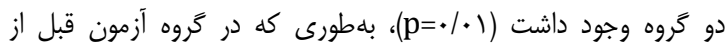

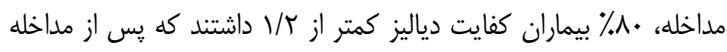

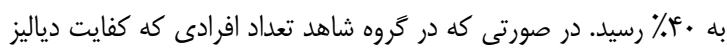

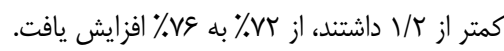

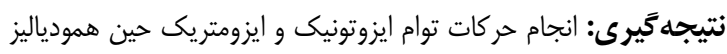

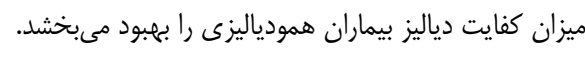
كليدوازهها: همودياليز، ايزوتونيك، ايزومتريك، كفايت دياليز

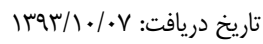

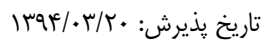

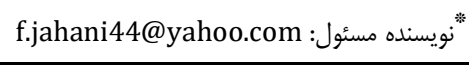

دوره rT، شماره ا، زمستان IraF

فصل نامه افق دانش 
FV تاثير حركات همزمان ايزوتونيك و ايزومتريك حين همودياليز بر كفايت دياليز

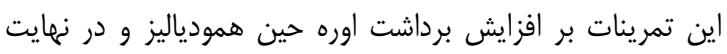

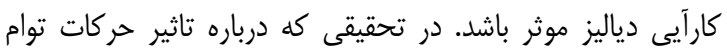

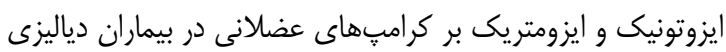

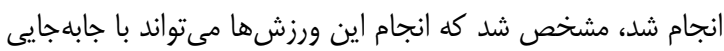

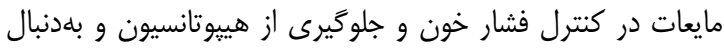
آن كرامٍ موثر واقع شود [24].

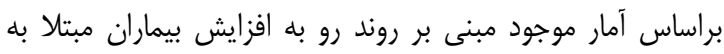

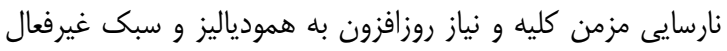

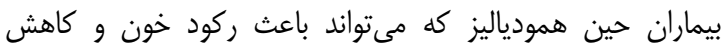

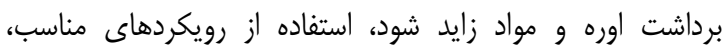

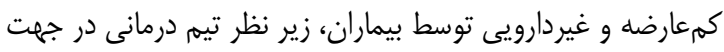

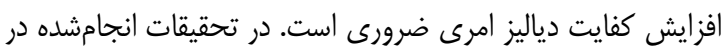

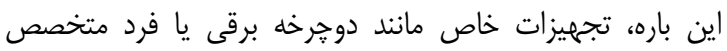

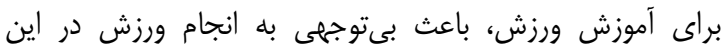

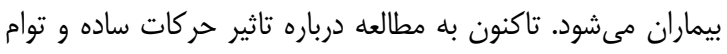

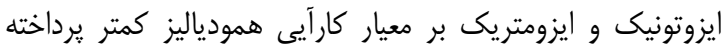

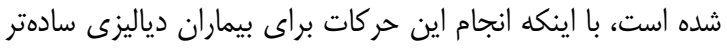

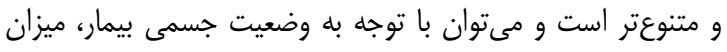
حركات را تعديل كرد.

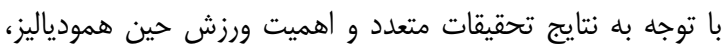

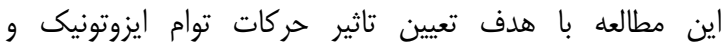

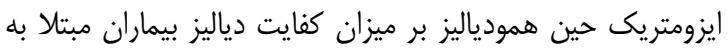
نارسايى مزمن كليه انجام شد.

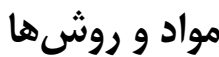

در اين كارآزمايى بالينى، •ه بيمار همودياليزى در دو مركز

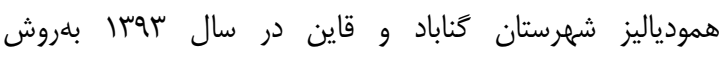

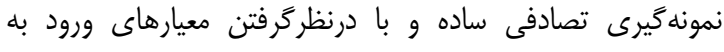

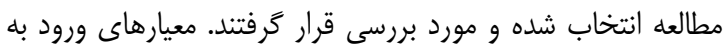

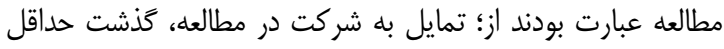

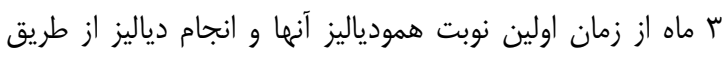

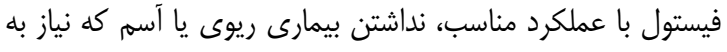

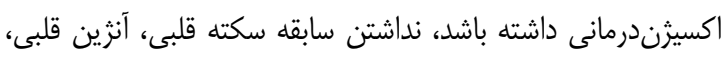

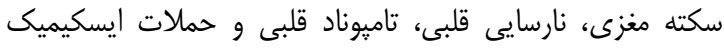

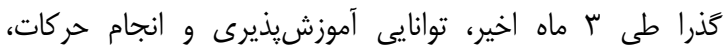

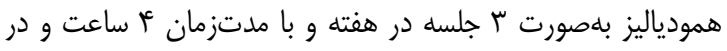

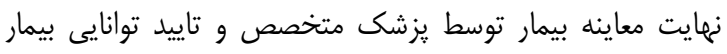

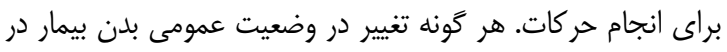

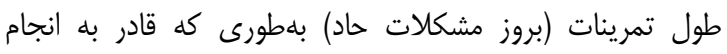

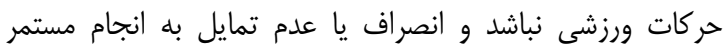

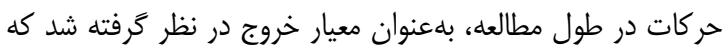
هيج يك از بيماران بهعلت متنوعبودن برنامه ورزشى (بهطورى كهر كه

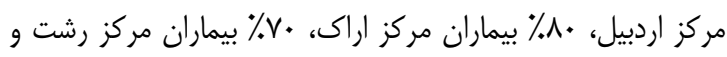

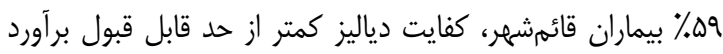

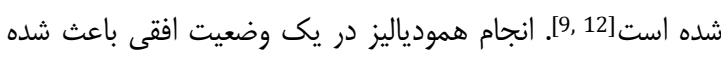

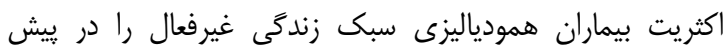

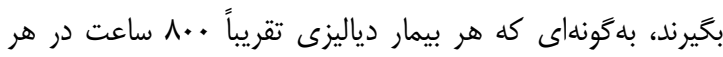

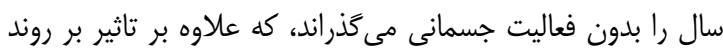

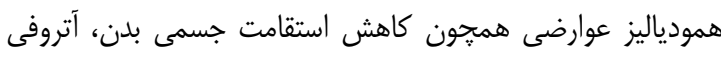

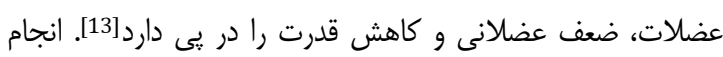

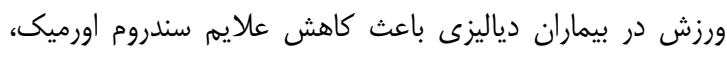

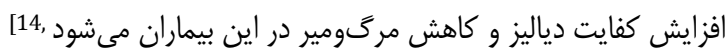

از ديدكاه فيزيولوزيك، ورزش حين دياليز با افزايش جريان خون

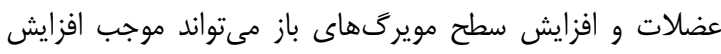

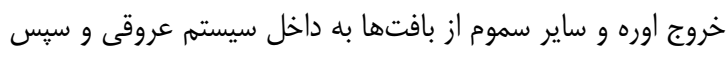

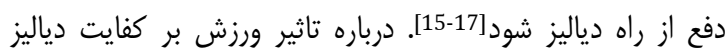

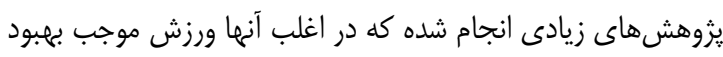

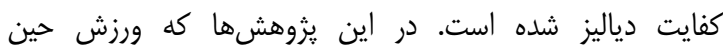

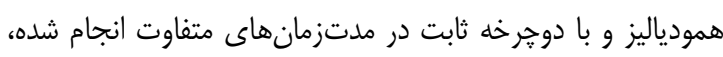

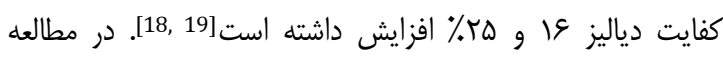

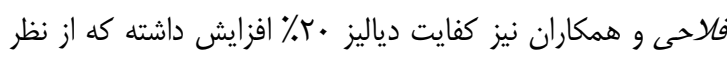

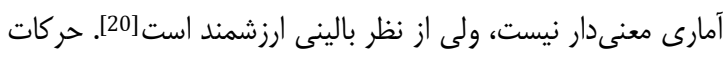

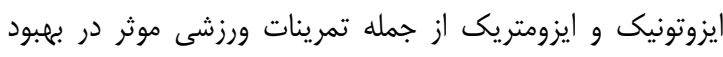

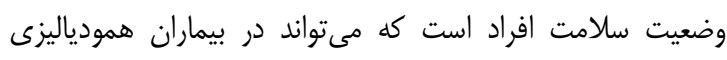
مورد بررسى قرار گيرد. در فعاليتهاى ايزوتونيك، عمل تلمبه عضلانى باعث افزايش

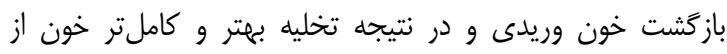

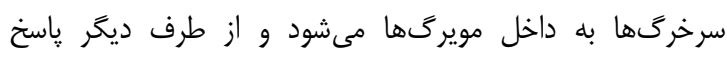

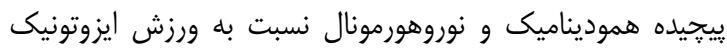
باعث انتقال اكسيثن و جذب آن توسط عضلات فعال مى شوردا.

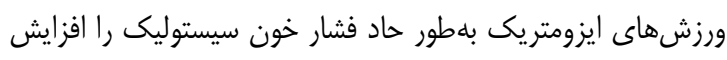

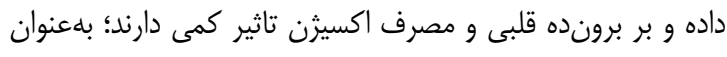

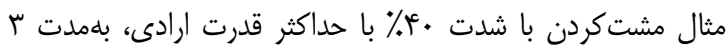

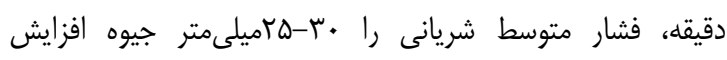

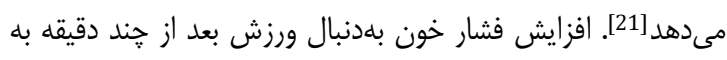

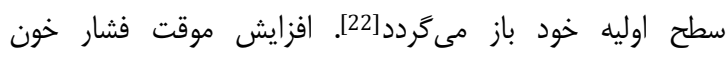

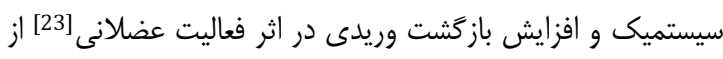

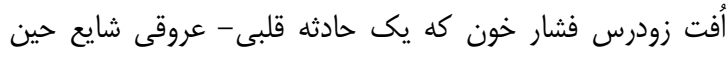

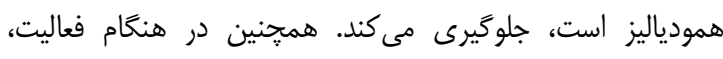

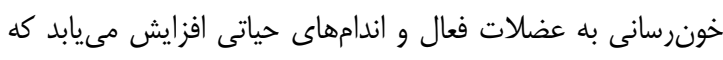

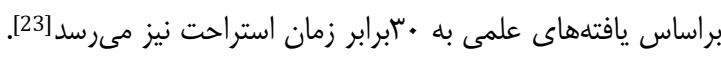

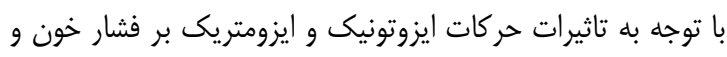

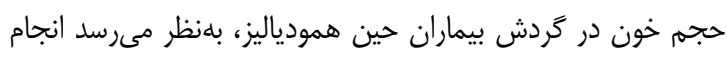


كوتاهى به بيمار داده مى شد (در زمان استراحت تصاويرى ديدنى از

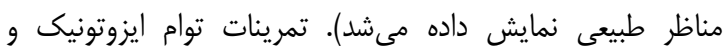

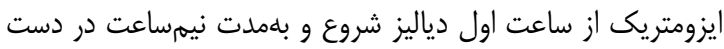

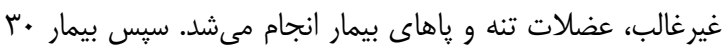

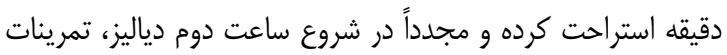

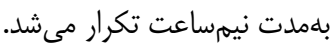

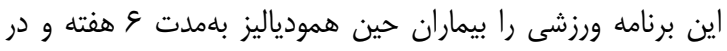

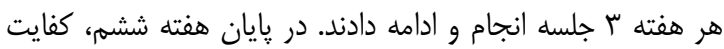

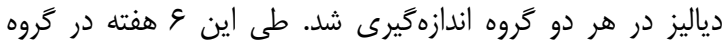
كنترل ورزشى انجام نشد. تعيين كفايت دياليز: بلمنظور تعيين كفايت دياليز، فرم اطلاعاتى

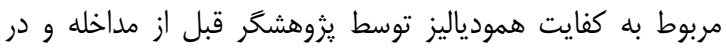

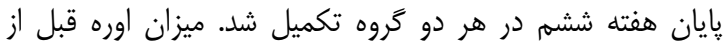

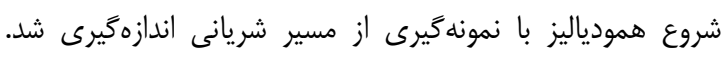

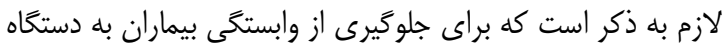
خاص همودياليز بهصورت كردشى از دستخاههاى مختلف استى استفاده

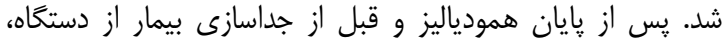

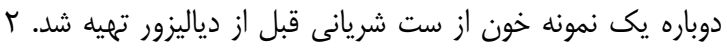

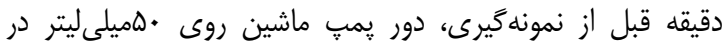

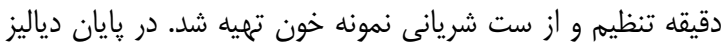

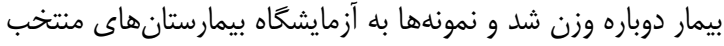
ارسال شد تا با يك نوع كيت انجام شود.

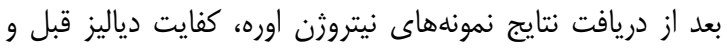

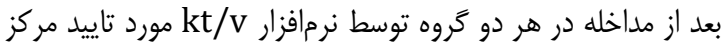

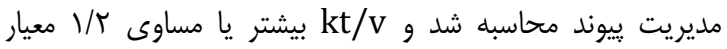
كفايت دياليز در نظر كرفته شد. دادهها با نرمافزار آمارى

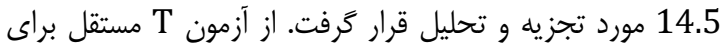

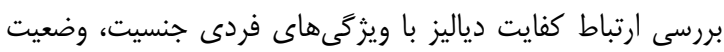

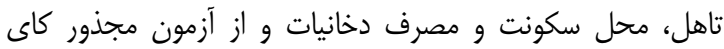

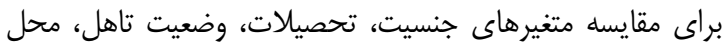

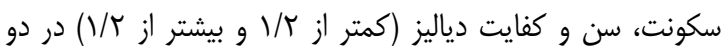

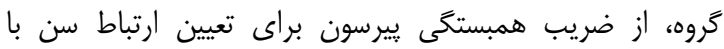

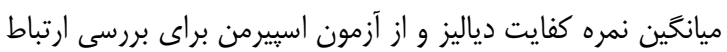
كفايت دياليز با سطح تحصيلات استفاده شد.

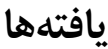

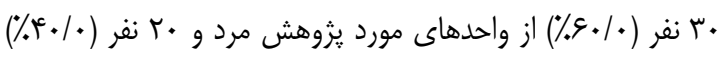

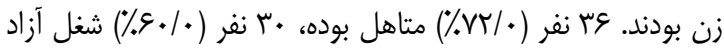

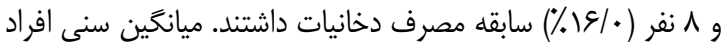

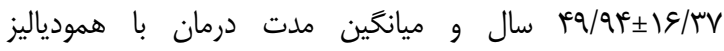

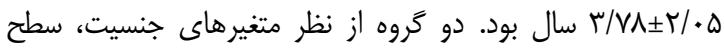

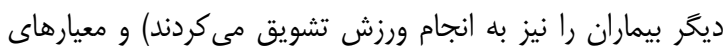
ورود مناسب، از مطالعه خارج نشدند.

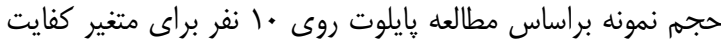

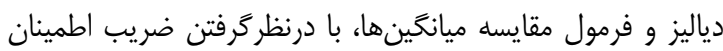

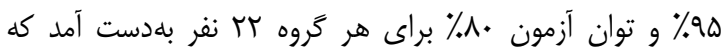

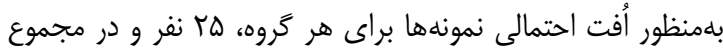

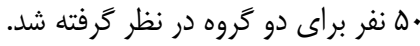

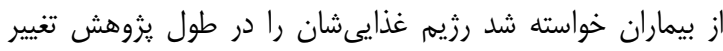
خاصى ندهند و سرعت جريان محلول دياليز ·.مهيلىليتر در دقيقه

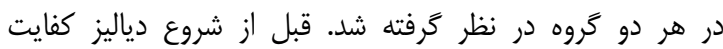

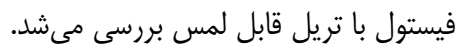

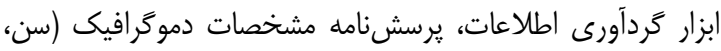
جنس، شغل، تحصيلات، تاهل، محل سكونت و مصرف درات دخانيات) و

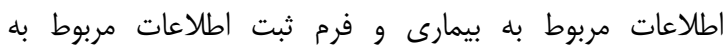

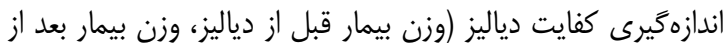

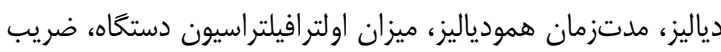

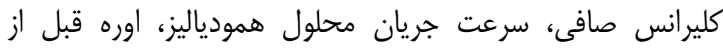
همودياليز و اوره بعد از دياليز) بود.

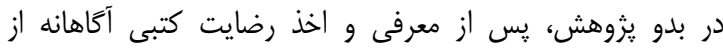

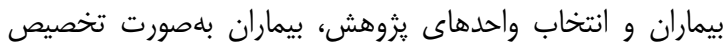

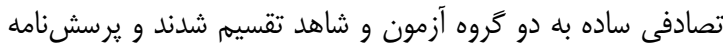

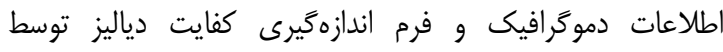

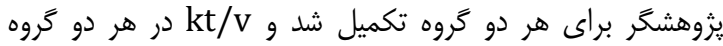

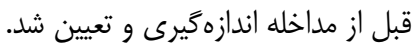

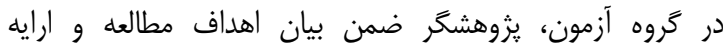

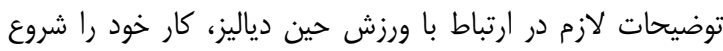

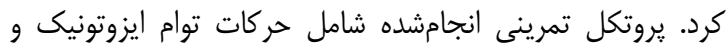

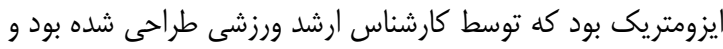

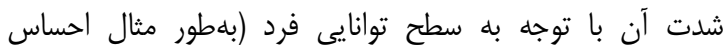

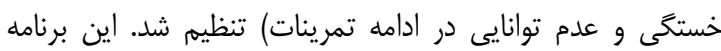

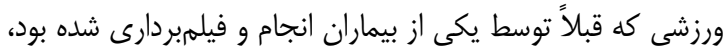

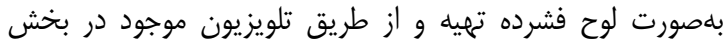

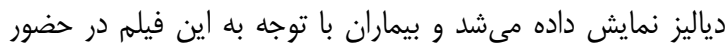

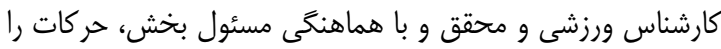

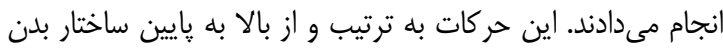

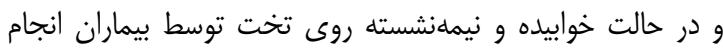

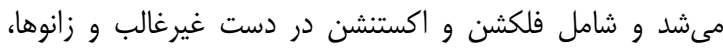

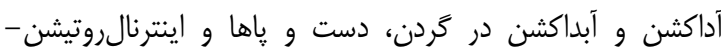

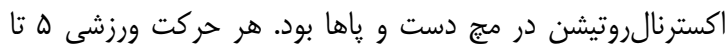

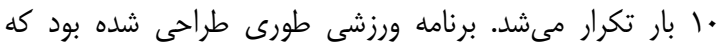

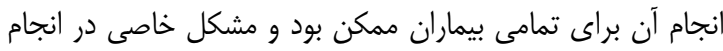
تمرينات وجود نداشت. همجنين يّ إن از انجام هر تمرين، استراحت 
تاثير حركات همزمان ايزوتونيك و ايزومتريك حين همودياليز بر كفايت دياليز وب

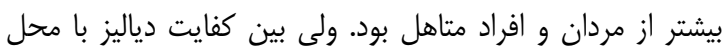

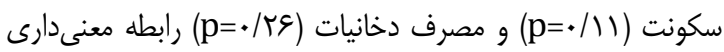

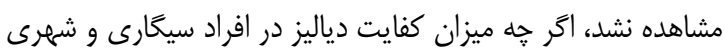

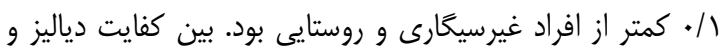

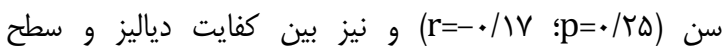

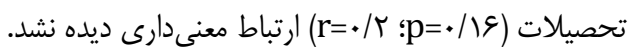

\section{بحث}

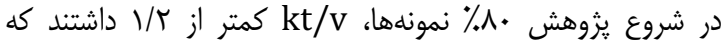

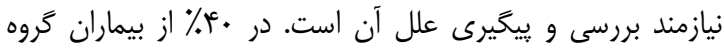

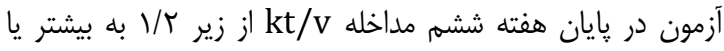

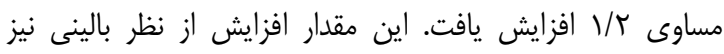

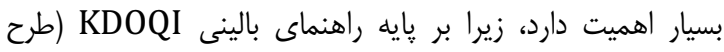

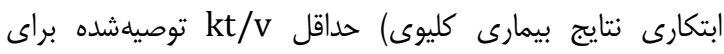

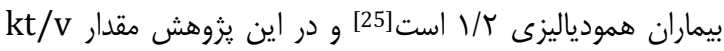

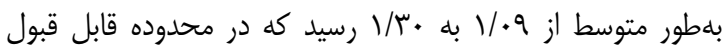

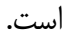

نتايج مطالعه تريشا و همكاران نيز افزايش معنىدارى در ميزان

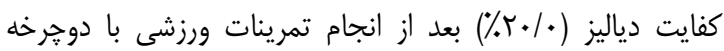

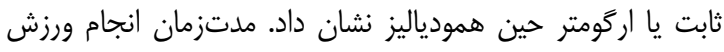

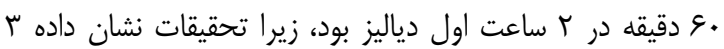
دوره زمانى هادقيقهاى ورزش حين همودياليز براى افزايش

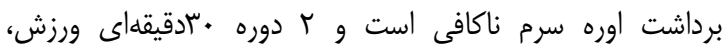

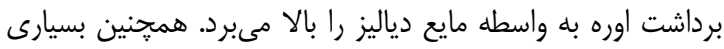

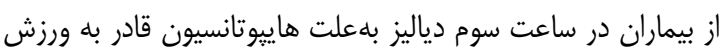

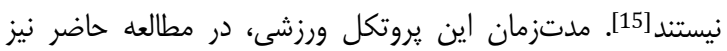

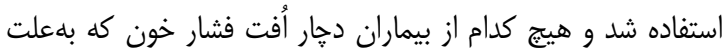

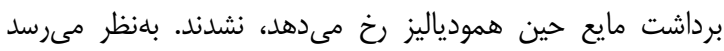

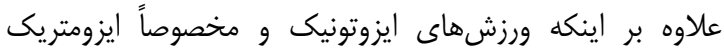
بهطور موقت باعث افزايش فشار خون مىشوند، ورزش در ساعت إنايكا

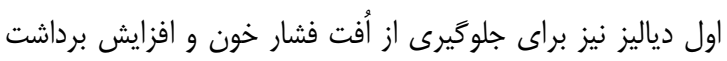

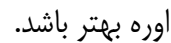
در مطالعه فلاحى و همكاران كفايت دياليز بعد از انجام يك دوره

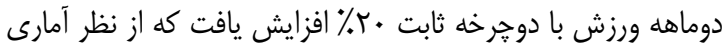

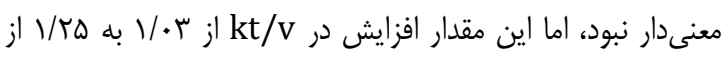
نظر بالينى حايز اهميت است [20]، هرا كه براساس اطلاعات سرات سيستم

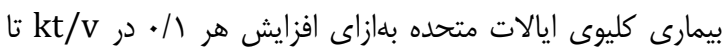

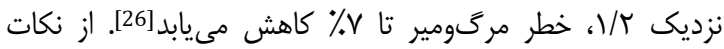

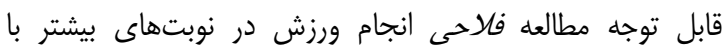

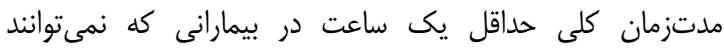

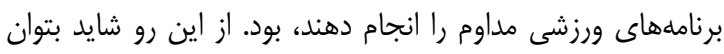

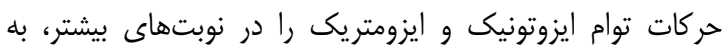

تحصيلات، وضعيت تاهل، محل سكونت و سن تفاوت معنىدارى

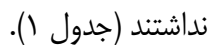

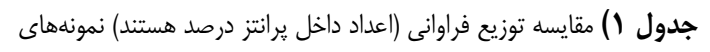
مورد يثروهش بر حسب خصوصيات دموَّرافيك در دو كروه آزمون (ها نفر نفر) و شاهد (هr نفر)

\begin{tabular}{|c|c|c|c|}
\hline سطح معنى دارى & تروه شاهد & كَروه آزمون & شاخص \\
\hline \multirow{2}{*}{$\cdot / T \Delta$} & $\mathbb{I}(\Delta \Gamma / \cdot)$ & $\operatorname{IV}(8 \mathrm{~N} \cdot)$ & جرد \\
\hline & $\operatorname{Ir}(\mathcal{F} N \cdot)$ & $\Lambda(T T / \cdot)$ & \\
\hline \multirow{4}{*}{. } & & & سطح تحصيلات \\
\hline & $\Delta(\mu \cdot / \cdot)$ & $9(\mu / \cdot)$ & ل لى سواد \\
\hline & $1 \cdot(j \cdot / \cdot)$ & $9(r / \cdot)$ & زير دييلم \\
\hline & $\left.1 \cdot()^{c} \cdot / \cdot\right)$ & $V(T N / \cdot)$ & يييلم و بالاتر \\
\hline \multirow{3}{*}{. } & & & وضعيت تاهل \\
\hline & $g(\Gamma \% / \cdot)$ & $\wedge(\mu r / \cdot)$ & جرد \\
\hline & $19(\mathrm{~V} / \cdot)$ & $\operatorname{IV}(\$ N / \cdot)$ & متاهل \\
\hline \multirow{3}{*}{$\cdot / \mathrm{VA}$} & & & محل سكونت \\
\hline & $\mathbb{I r}\left(F^{\mathrm{N} N} / \cdot\right)$ & $11(\kappa \% / \cdot)$ & ستا \\
\hline & $\Pi(\Delta T / \cdot)$ & If $(\Delta F / \cdot)$ & en \\
\hline \multirow{3}{*}{.1 .9} & $V(T N / \cdot)$ & $9(\Gamma / \cdot)$ & 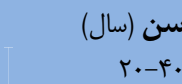 \\
\hline & $\|(\kappa \kappa / \cdot)$ & $f(\mid s / \cdot)$ & f.-. \\
\hline & $V(T N / \cdot)$ & $I T(F N / \cdot)$ & $4 \cdot-1$ \\
\hline
\end{tabular}

قبل از مداخله، تفاوت آمارى معنىدارى بين دو كروه از نظر كفايت

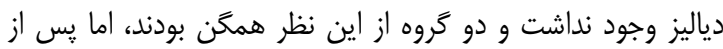

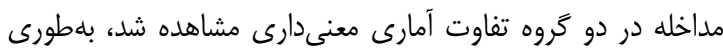

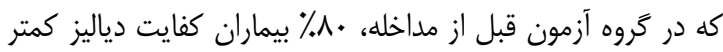

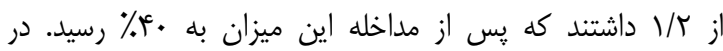

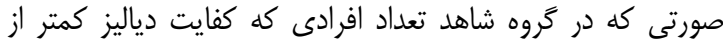

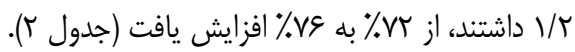

جدول T) مقايسه توزيع فراوانى (اعداد داخل يرانتز درصد هستند) كفايت دياليز

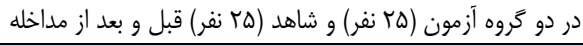

\begin{tabular}{|c|c|c|c|}
\hline سطح معنى دارى & كروه شاهد & كروه آزمون & مراحل \\
\hline \multirow{3}{*}{$.10 \mid$} & & & قبل از مداخله \\
\hline & $M(V T / \cdot)$ & $r \cdot(\Lambda \cdot / \cdot)$ & كمتر از r/ kt/v \\
\hline & $V(T N \cdot)$ & $\Delta(r \cdot / \cdot)$ & 1/ بيشتر از kt/v \\
\hline \multirow{3}{*}{.$/ .1$} & & & بعد از مداخله \\
\hline & $19(v \& / \cdot)$ & $1 \cdot(\kappa \cdot / \cdot)$ & كمتر از kt/v \\
\hline & $\varepsilon(\pi \%)$ & $10(8.1)$. & kt/v بيشتر از kt/v \\
\hline
\end{tabular}

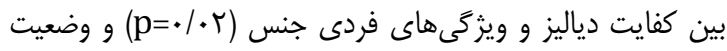

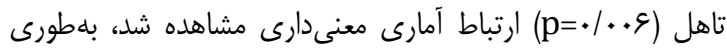
كه ميانكين كفايت دياليز در زنان و افراد مجرد بلهطور معنىدارى آناط 
علىرغم تاثيرات مفيد ورزش بر كارآيى همودياليز، انجام

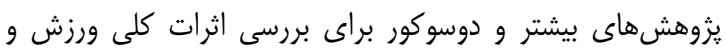

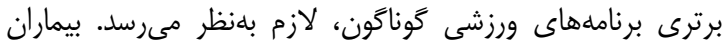

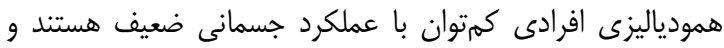

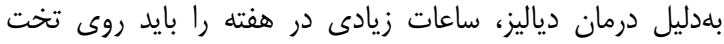

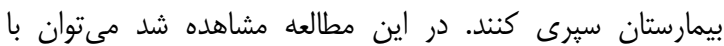
بهكاركيرى تمرينات ورزشى ساده ايزوتونيك و ايزومتريك و بدون ماندان

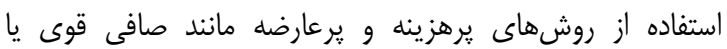

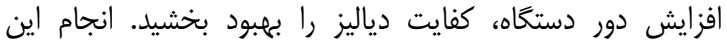

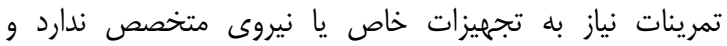

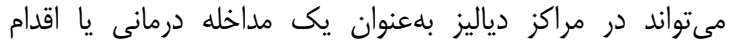

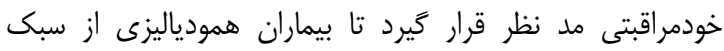

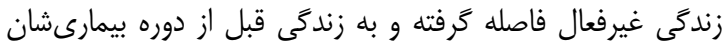
نزديك شوند.

\section{نتيجه كَيرى}

انجام حركات توام ايزوتونيك و ايزومتريك حين همودياليز مىتواند

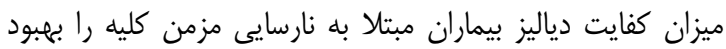

تشكر و قدردانى: بدين وسيله از همكارى صميمانه كاركنان و

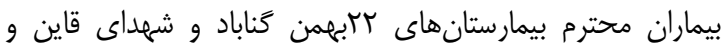
همجِنين خانم روحانى كه در تدوين و انجام برنامه ورزشى يارئر ما بودند، تقدير و تشكر مىشود. تاييديه اخلاقى: اين يزوهش توسط كميته منطقهاى اخلاق در

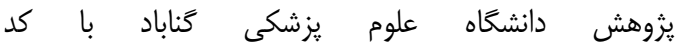
اير ان با شماره GMU.ERC.1392.27 تصويب و در مركز ثبت كارآزمايى بالينى ايران با شماره 2013103015223N1 ثبت شد. تعارض منافع: موردى توسط نويسندكان گزارش نشده است.

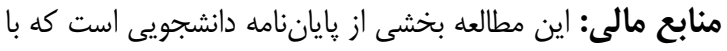

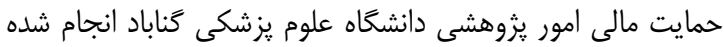

\section{منابع}

1- Shafipour V, Jafari H, Shafipour L. The relationship between stress intensity and life quality in hemodialysis patients hospitalized in Sari Iran. Q J Sabzevar Univ Med Sci. 2009;16(3):155-60. [Persian] 2-Tayyebi A, Babahaji M, Sadeghi Sherme M, Ebadi A, Eynollahi B. Study of the effect of Hatha Yoga exercises on dialysis adequacy. Iran J Crit Care Nurs. 2012;4(4):183-90. [Persian]

3-Vahed Parast H, Ravanipour M. Assessing the adequacy of dialysis in patients undergoing hemodialysis in hemodialysis center in Boshehr City. Sci J Hamadan Nurs Midwifery Fac. 2008;16(2):50-4. [Persian]
بيمارانى كه از نظر جسمى ضعيفتر هستند توصيه كرد. در مقابل در مطالعه رياحى و همكاران نتايج بيانكر اين بود كه انجام تمرين

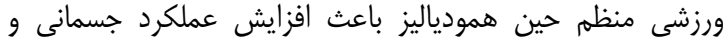
كاهش آتروفى عضلانى مىشود، ولى بر كيفيت دياليز آنها تاثير

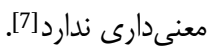
در يزوهش حاضر كفايت دياليز در زنان بلطور معنىدارى بيشتر از

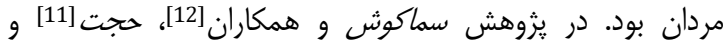
همجنين مطالعه مقرب و همكاران [27] كفايت دياليز در بيماران زئن

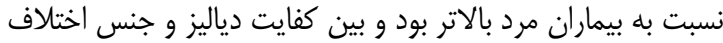
معنى دارى وجود داشت. سماكوش علت اين مساله را صافى دياليز مشابه در هر دو جنس و در نتيجه انجام دياليز بهتر براى زنان إن بان

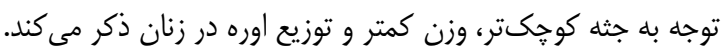

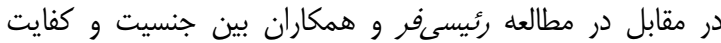
دياليز ارتباط آمارى معنى دارى مشاهده نشد [28]. همجنين در مطالعه حاضر كفايت دياليز بهطور معنى دارى در در افراد

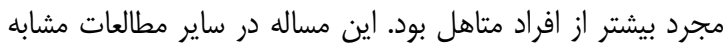
يافت نشد و ممكن است بلهعلت سن كمتر و انجام ورزش با بدر إندرت

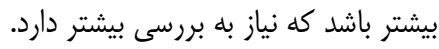

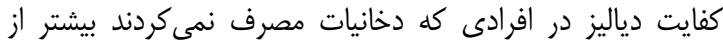

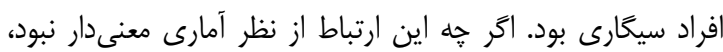

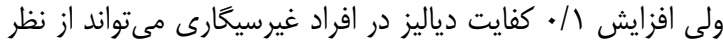

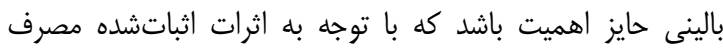
دخانيات نتيجه دور از انتظارى نيست. با توجه به مطالعاتى كه در ايران در زمينه كفايت دياليز انجام شده،

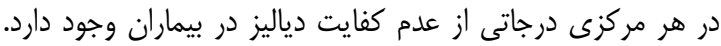

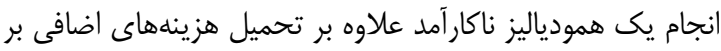

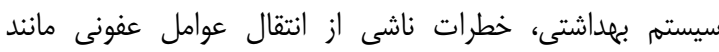

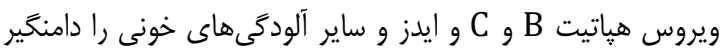

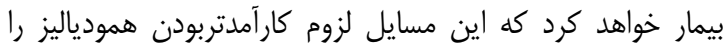

مشخص مى منمايد [29].

ورزش حين همودياليز با افزايش جريان خون عضلات و سطح

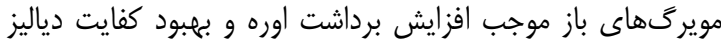

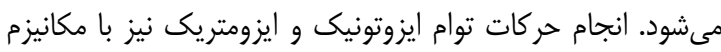

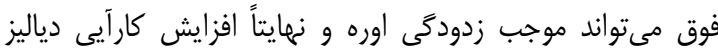

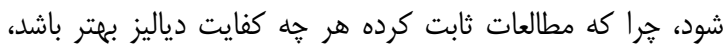

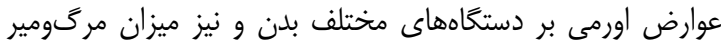
كاهش مى يابد [28]. از محدوديتهاى اين مطالعه عدم دسترسى به تعداد نمونه كافى در

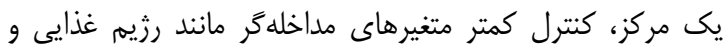
دسترسى عروق نامناسب و نبودن امكانات كافى براى رصد بيماران

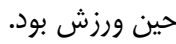


FI تاثير حركات همزمان ايزوتونيك و ايزومتريك حين همودياليز بر كفايت دياليز practice in ESRD. Am J Kidney Dis. 2005;45(5):912-6. 17- Kong CH, Tattersall JE, Greenwood RN, Farrington K.. The effect of exercise during hemodialysis on solute removal. Nephrol Dial Transplant. 1999;14(12):2927-31. 18- Sun Y, Chen B, Jia Q, Wang J. The effect of exercise during hemodialysis on adequacy of dialysis. Zhonghua Nei Ke Za Zhi. 2002;41(2):79-81. [Chinese]

19- Zaluska A, Zaluska WT, Bednarek-Skublewska A, Ksiazek A. Nutrition and hydration status improve with exercise training using stationary cycling during hemodialysis (HD) in patients with end stage renal disease (ESRD). Ann Univ Mariae Curie Sklodowska Med. 2002;57(2):342-6.

20- Fallahi MJ, Shahidi Sh, Farajzadegan Z. The effect of intradialytic exercise on dialysis efficacy, serum phosphate, hemoglobin and blood pressure control and comparison between two exercise programs in hemodialysis patients. J Isfahan Med Sch. 2008;26(89):152-61. [Persian]

21- Tanaka S, Sugiura T, Yamashita S, Dohi Y, Kimura G, Ohte N. Differential response of central blood pressure to isometric and isotonic exercises. Sci Rep. 2014;4:5439.

22- Parsons TL, Toffelmire EB, King-Van Vlack CE. The effect of an exercise program during Hemodialysis on dialysis efficacy, blood pressure, and quality of life in end-stage renal disease patients. Clin Nephrol. 2004;61(4):261-74.

23- Lakshemi NS. Therapeutic exercise. Daneshmandi H, Shamsi Majelan A, Mobarak Abadi L, translators. Tehran: Nasima; 2005. pp. 44-5.

24- Yaghobi M, Mohammadi I, Ahmadi F. Effect of Isotonic and Isometric Exercise Box on muscular Cramping pain During Hemodialysis. J Kurdistan Univ Med Sci. 2007;12(2):53-60. [Persian]

25- Jindal KK, Manuel A, Goldstein MB. Percent reduction in blood urea concentration during hemodialysis (PRU): A simple and accurate method to estimate Kt/V urea. ASAIO Trans. 1987;33(3):286-8.

26- Borzou R, Ghalyaf M, Amini R, Zandiyan M, Torkaman B. Effect of increased blood flow on the amount of dialysis adequacy in hemodialysis patients. J Shahrkord Univ Med Sci. 2005;8(2):60-6. [Persian]

27- Mogharab M, Madarshahian F, Rezai N, Mohammadi A. Dialysis adequacy in choronic hemodialysis patients in educational center Vali-Asr in Birjand. J Brijand Univ Med Sci. 2010;17(3):206-14. [Persian]

28- Raiesifar A, Torabpour M, Mohsenizad P, Sha'bani H, Tayyebi A, Masoumi M. Dialysis adequacy in patients of Abadan hemodialysis center. J Crit Care Nurs. 2009;2(3):87-90. [Persian]

29- Nadi E, Bashirian S, Khosravi M. Survey dialysis adequacy in Ekbatan hemodialysis part Sci. J Hamedan Univ Med Sci. 2003;10(3):27-33. [Persian]
4- Chang TI, Li S, Chen SC, Peralta CA, Shlipak MG, Fried $\mathrm{LF}$, et al. Risk factors for ESRD in individuals with preserved estimated GFR with and without albuminuria: results from the Kidney Early Evaluation Program (KEEP). Am J Kidney Dis. 2013;61(4 Suppl 2):S4-11.

5- Mottahedian Tabrizi E, Najafi Mehri S, Samiey S, Einollahi B, BabaeiGh, Mohammadi E. Effect of programmed nursing cares in prevention of hemodialysis Complications. Iran J Crit Care Nurs. 2009;2(2):55-9. [Persian]

6- Tayyebi A, Shasti S, Tadrisi D, Eynollahi B, Sadeghi Sherme M. The relationship between blood pressure and dialysis adequacy in dialysis patients. Iran J Crit Care Nurs. 2012;5(1):49-52. [Persian]

7- Riahi Z, Esfarjani F, Marandi M, Bayat A, Kalani N. The effects of regular exercise program on dialysis efficacy, muscle atrophy and physical performance in hemodialysis patients. J Sharekord Univ Med Sci. 2012;14(5):63-73. [Persian]

8- Chauveau P, Nguyen H, Combe C, Chêne G, Azar R, Cano $\mathrm{N}$, et al. Dialyzer membrane permeability and survival in hemodialysis patients. Am J Kidney Dis. 2005;45(3):565-71.

9- Shahdadi H, Badakhsh M, Msynayy N, Heydari M, Rahnema M. The effect ofincreasing blood flow rateon complications and dialysis adequacy in hemodialysis patients with low KT/V. Iran J Nurs Res. 2010;5(17):627. [Persian]

10- Henrich WL. Principles and practice of dialysis. $4^{\text {th }}$ edition. Philadelphia: Lippincott Williams \& Wilkins; 2009.

11- Hojjat M. Hemodialysis adequacy in patients with chronic renal failure. Iran J Crit Care Nurs. 2009;2(2):616. [Persian]

12- Abedi Samakoosh M, Aghaie N, Gholami F, Shirzad M, Yosefi E, Teymoorzadeh Baboli T. Assesment dialysis adequacy in hemodialysis patients of Qaemshar Razi Hospital. J Mazandaran Univ Med Sci. 2013;23(107):207. [Persian]

13- Chojak K, Smolenski O, Milkowski A, Pitrowski W. The effects of 6-month physical training conducted during hemodialysis in ESRD patients. Med Rehabil. 2006;10(2):25-41.

14-Stack AG, Molony DA, Rives T, Tyson J, Murthy BV. Association of physical activity with mortality in the US dialysis population. Am J Kidney Dis. 2005;45(4):690701.

15- Parsons TL, Toffelmire EB, King-VanVlack CE. Exercise training during hemodialysis improves dialysis efficacy and physical performance. Arch Phys Med Rehabil. 2006;87(5):680-7.

16- Cheema BS, Smith BC, Singh MA. A rationale for intradialytic exercise training as standard clinical 